\title{
The Effects of Principals' Digital Leadership on Teachers' Digital Teaching during the Covid-19 Pandemic in Malaysia
}

\section{N. Hafiza Hamzah ${ }^{1}$ \\ M. Khalid M. Nasir ${ }^{\star}$ (DD \\ Jamalullail Abdul Wahab ${ }^{3}$}

${ }_{1,2,3}$ Faculty of Education, Universiti Kebangsaan Malaysia (UKM), Malaysia.

Email:nurhafiza hamzah@yahoo.com Tel:+60133694123

sEmail:mdkhalid@ukm.edu.mvTel:+601115154449

${ }^{3}$ Email:jamall64@ukm.edu.my Tel: +60132313922

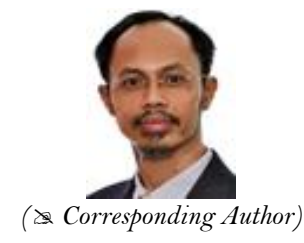

Abstract

Education involving digital technology is the latest transformation of the education system, especially during the occurrence of the COVID-19 pandemic. The Malaysian Ministry of Education (MOE) has taken the initiative to spearhead efforts to develop the skills and potential of students in the use of digital technology. The main purpose of this study was to identify the level of digital leadership displayed by principals, the level of teachers' digital teaching practices and the elements of principals' digital leadership that predict the level of teachers' digital teaching. About 400 secondary school teachers in Hulu Langat District, Selangor were involved in this study. The findings of this study show that the level of digital leadership displayed by principals and teachers' digital teaching practice are both at a high level. However, the positive correlation between the two is moderate. Multiple regression found that only digital citizenship is a strong predictor of teachers' digital teaching. The findings show that the ability to plan and organize digital leadership programs is important and can help improve students' academic performance, despite the COVID-19 pandemic crisis.
Citation | N. Hafiza Hamzah; M. Khalid M. Nasir; Jamalullail Abdul Wahab (2021). The Effects of Principals' Digital Leadership on Teachers' Digital Teaching during the Covid-19 Pandemic in Malaysia. Journal of Education and e-Learning Research, 8(2): 216221.

History:

Received: 23 February 2021

Revised: 29 March 2021

Accepted: 3 May 2021

Published: 26 May 2021

Licensed: This work is licensed under a Creative Commons

Attribution 3.0 License (cc) EY

Publisher: Asian Online Journal Publishing Group
Acknowledgement: All authors contributed to the conception and design of the study.

Funding: This research is funded by the Faculty of Education, the Universiti Kebangsaan Malaysia (UKM) under the project code GG-2019-021 and GG2020-019.

Competing Interests: The authors declare that they have no conflict of interests.

Transparency: The authors confirm that the manuscript is an honest, accurate, and transparent account of the study was reported; that no vital features of the study have been omitted; and that any discrepancies from the study as planned have been explained.

Ethical: This study follows all ethical practices during writing.

\section{Contents}

1. Introduction

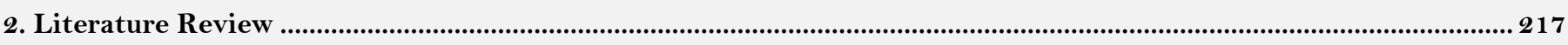

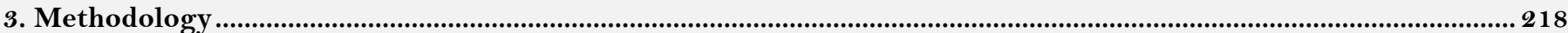

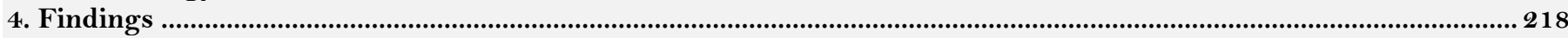

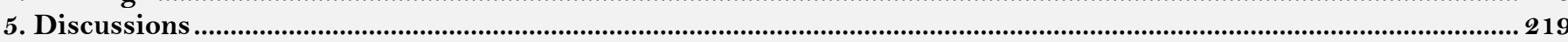

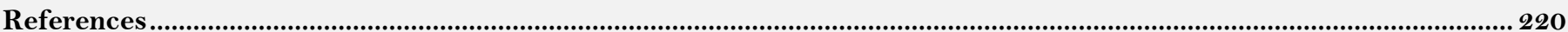




\section{Contribution of this paper to the literature}

This paper provides guidelines for readers and authorities to organize appropriate leadership programs and provide encouragement and motivation for school administrators to achieve digital leadership characteristics.

\section{Introduction}

The world of education is increasingly challenging, especially in the digital era which demands that school leaders cultivate the use of digital technology in school administration and management. The Malaysian Ministry of Education (MOE) has produced the ICT Transformation Plan 2019-2023, which was launched to support the digital education agenda in Malaysia (Ministry of Education Malaysia, 2019). Principals are required to train themselves to master digital technology skills, including the possession of digital technology-focused leadership characteristics (Yusof, Yaakob, \& Ibrahim, 2019). Teachers are also encouraged to master ICT and digital technology competencies so as not to experience difficulties in implementing these changes (Tomte, 2013). Thus, to achieve transformation in education school principals and teachers are required to use these skills to improve students' academic performance, using the methods of digital technology.

Principals wanting to implement digital leadership need to wisely use their space and opportunities to bring great changes to the school culture and thus have a positive impact on the education system in Malaysia, which aims to use the elements of technology and digital mastery to enhance student marketability in the 4.0 era of education (Bahtiar, Ibrahim, Ariffin, Ismail, \& Isa, 2014). Principals need to identify the best approach to ensure the effective involvement of both teachers and students (Arokiasamy, Abdullah, \& Ismail, 2014; Norakmar, Noor, \& Latif, 2019). According to Thannimalai and Raman (2018), the responsibilities of teachers have become more complex, as they need to be committed to discovering various alternatives to support the integration of digital technology in teaching and learning. Students are enthusiastic about digital learning and the use of digital devices such as mobile phones, tablets and so on because they want to get internet access (Arip et al., 2019).

According to Sheninger (2014), there are still school leaders who are reluctant and misunderstand the use of digital technologies, such as the role of social media and the advantages of using digital devices. Some principals do not master ICT and digital technology competencies. According to Leong, Chua, and Sathiamoorthy (2016), there is a correlation between the knowledge of technology integration and principals' ability to motivate themselves to implement whole school changes. Van Niekerk and Van Wyk (2014) also argue that the principal is the leader who must initiate and sustain the integrated use of technology in education by modeling and incorporating technology into their daily management and administrative practices. Karahan, Canbazoğlu Bilici, and Ünal (2015) discovered that the need for school administrators to adapt to technological developments is crucial, as technological developments will continue to occur. This study aims to investigate the level of digital leadership displayed by principals through the dimensions of visionary leadership, digital era learning culture, professional practice excellence, systemic improvement and digital citizenship. In addition, this study also identified elements in principals' digital leadership that can predict teachers' digital teaching.

\section{Literature Review}

School leaders today must strive to fill any gaps in their technological knowledge and skills in order to provide direction and guidance to lead digital development in their school and spread this practice to the school learning environment (Aksal, 2015). The use of teaching aids in teaching and learning is important to attract students' interest and improve their performance, as well as achieve the teacher's objectives in teaching a subject (Sallehin, Halim, Education, Tun, \& Onn, 2015). Petersen (2014) has noted that school administrators have taken the initiative to learn about the use of technology on their own accord; they plan teacher training programs using technology and carry out school management and school leadership tasks using digital technology devices. Principals' efficient management of the education system will help to have an effective impact on teachers' teaching practices and digital learning systems (Bernhardt, 2015). The use of technology has supported learning in the classroom, leading to increased student achievement, bridging the student achievement gap and reducing the number of students dropping out of school. Meanwhile, Domeny (2017) showed that there is no significant relationship between principals' digital leadership and the implementation of digital learning by teachers - the relationship between the two variables is weak. However, others have still found a strong relationship between the two dimensions (International Society for Technology in Education (ISTE), 2021). The overall ISTE Standards for Administrators demonstrate that ISTE-A offers strong standards to guide and direct principals in their role as digital leaders.

Digital leadership is the leadership to bring about change using digital devices in the field of educational management. This transformation process requires leaders to intensify their efforts to mobilize, implement and absorb the use of digital devices as a medium of teaching and learning through strategic planning aligned with the vision of the school (International Society for Technology in Education (ISTE), 2021). The ISTE has issued a digital leadership standard for administrators, the ISTE Standard for Administrators (ISTE-A). This standard serves as a working guide for all school administrators in cultivating digital teaching and learning. The ISTE-A Standard sets out five dimensions of digital leadership, namely visionary leadership, digital era learning culture, excellence in professional practice, systemic improvement and digital citizenship. ISTE also recommends that leaders allocate an appropriate amount of time and training on an ongoing basis to the competencies of teachers in order to ensure the smoothness of the implementation of the vision to expand digital education.

Digital leadership is characterized by transformational leadership styles and the use of digital technology. In this theory, leaders model behavior, and employees will be inspired to follow suit (Bass, 1989). This style of transformational leadership never changes, it only adapts to the context. It can be used in all fields but is particularly important in fields that are adapting to quickly changing technology, where innovation and agility are required. Digital teaching is teaching that integrates digital technology in student learning. It can take place in all areas of the curriculum (Victoria State Government, 2020). Teacher quality factors are important for an effective teaching system in order to improve student achievement (Norakmar, Noor, \& LAtif, 2020). One of the indicators 
of teacher quality is the mastery of digital competencies. A study by Jannah, Prasojo, and Jerusalem (2020) shows that the main factor determining the success of digital-based learning is not only the availability of digital devices, but the competencies that must be mastered by teachers.

Several studies mention barriers to the integration of digital technology in learning, such as the fact that teachers are unable to use digital technology in the classroom due to lack of knowledge, skills, training, and selfconfidence as well as limited facilities (Vinathan, 2017). According to Gupta (2018), because teachers do not explore course materials well and do not want to use that time to do coursework or exercises, digital teaching will depend on the teacher's computer literacy level and burdens the teacher with the task of determining learning effectiveness through student assessment. The report by the Organization for Economic Cooperation and Development (OECD) also outlines issues preventing the implementation of teaching and learning in digital environments, such as limited access to and usage of computers. Students are using mobile devices for purposes that are not educational and the level of student inclination for the use of digital devices leads to different performance effects (Organisation for Economic Cooperation and Development [OECD], 2019).

\section{Methodology}

This study is quantitative in nature and was conducted using a cross-sectional survey approach for the purpose of examining the level of digital leadership practices of principals in the integration of digital learning in schools. The ISTE Standard for Administrators (ISTE-A) is a fundamental element in the formation of this study construct. The population of teachers consists of 4450 teachers who are currently teaching in national secondary schools in Hulu Langat District, Selangor. Sampling tables were referenced to determine the sample methods (Krejcie \& Morgan, 1970). An appropriate sample size of 402 participants was selected as a purposed sampling. All secondary school teachers of Hulu Langat District were invited to participate in this study. The researcher distributed the questionnaire to all the teachers involved, with permission from the school principals. The questionnaires were provided using Google Forms. Two instruments used for this study were the Principal Technology Leadership Assessment (PTLA) released by the International Society for Technology in Education (ISTE) (2021) and the Teacher Technology Self-Efficacy Study (ETS-ES), adapted from Domeny (2017) to focus on the use of digital technology by teachers.

The survey consists of 3 parts, namely part A, the demographic profile of the respondents; part B, 32 items covering the dimension of digital leadership; and part C, 50 items covering the dimension of digital teaching in the classroom. The survey as a whole was also reviewed by experts in the field of educational administration to ensure the validity of its content (Awang, Afthanorhan, Mamat, Sultan, \& Abidin, 2016). The survey answers use a 5 point Likert scale: from Strongly Disagree to Strongly Agree. A pilot study was conducted in two schools in Hulu Langat District involving 30 samples. The reliability of the whole instrument also recorded a high Cronbach's Alpha $(\alpha)$ value of 0.93 .

Quantitative data analysis was carried out using SPSS version 27. Descriptive analysis was conducted involving frequency, percentage, mean score, standard deviation and interpretation of mean score. Meanwhile, inferential analysis and multiple regression analysis was carried out to identify the correlation between principals' digital leadership and teachers' digital teaching.

\section{Findings}

Out of 402 distributed questionnaires, 357 were returned, meaning that the return rate was $89 \%$. Of these, however, only 318 were fully completed and used for the analysis. A majority of the respondents (87\%) were female teachers. Of the teachers, $36 \%$ indicated they had more than 20 years' teaching experience, followed by $33 \%, 18 \%$ and $11 \%$ of teachers with teaching experience in the range of 16 to 19 years, 11 to 15 years, and 5 to 10 years respectively. Only $2.5 \%$ of respondents had less than 5 years' teaching experience. It was also noted that the number of teachers who had or had not attended digital teaching related training courses in the use of digital devices was approximately equivalent.

The overall level of Principals' Digital Leadership and its components were high. The mean score of each dimension was more than 3.88, and the standard deviation more than .48, as shown in Table 1 . The summated score of Principals' Digital Leadership was normally distributed (skewness at -.76) and the reliability was .97.

\begin{tabular}{l|c|c|c}
\multicolumn{4}{c}{ Table-1. Level of principals' digital leadership. } \\
\hline Dimension & Mean Score & Standard Deviation & Level \\
\hline Visionary Leadership & 4.09 & 0.53 & High \\
\hline Digital Era Learning Culture & 4.08 & 0.55 & High \\
\hline Professional Practice Excellence & 3.93 & 0.65 & High \\
\hline Systemic Improvement & 3.88 & 0.65 & High \\
\hline Digital Citizenship & 4.07 & 0.55 & High \\
\hline Overall & 4.01 & 0.48 & High \\
\hline
\end{tabular}

\begin{tabular}{l|c|c|c}
\multicolumn{4}{c}{ Table-2. Level of teachers' digital teaching practice. } \\
\hline Dimension & Mean Score & Standard Deviation & Level \\
\hline Digital Era Learning & 4.05 & 0.41 & High \\
\hline Digital Era Work Culture & 3.87 & 0.53 & High \\
\hline Student Learning & 3.99 & 0.46 & High \\
\hline Teacher Digital Citizenship & 4.02 & 0.46 & High \\
\hline Professional Enhancement & 3.98 & 0.48 & High \\
\hline Overall & 3.98 & 0.36 & \\
\hline
\end{tabular}

The overall level of Teachers' Digital Teaching Practice and its components were high as well. The mean score of each dimension was more than 3.87, and the standard deviation more than 0.36, as shown in Table 2. The 
summated score of Teachers' Digital Teaching Practice was normally distributed (skewness at .42) and the reliability was .97 .

A statistically significant association was discovered between principals' digital leadership and teachers' digital teaching practice. Both constructs fulfilled the assumption of normality. Thus, the Pearson statistic was calculated, $r(316)=.53, p<.01$. This result has shown the existence of a significant positive relationship between the two constructs, meaning that principals who have a high level of digital leadership tend to inspire a higher level of digital teaching practice in their teachers. The effect size is small for studies in this area. The $r^{2}$ indicates that nearly $30 \%$ of the variance in principals' digital leadership can be predicted from their teachers' digital teaching practice. The scatter plot in Figure 1 visualizes the association.

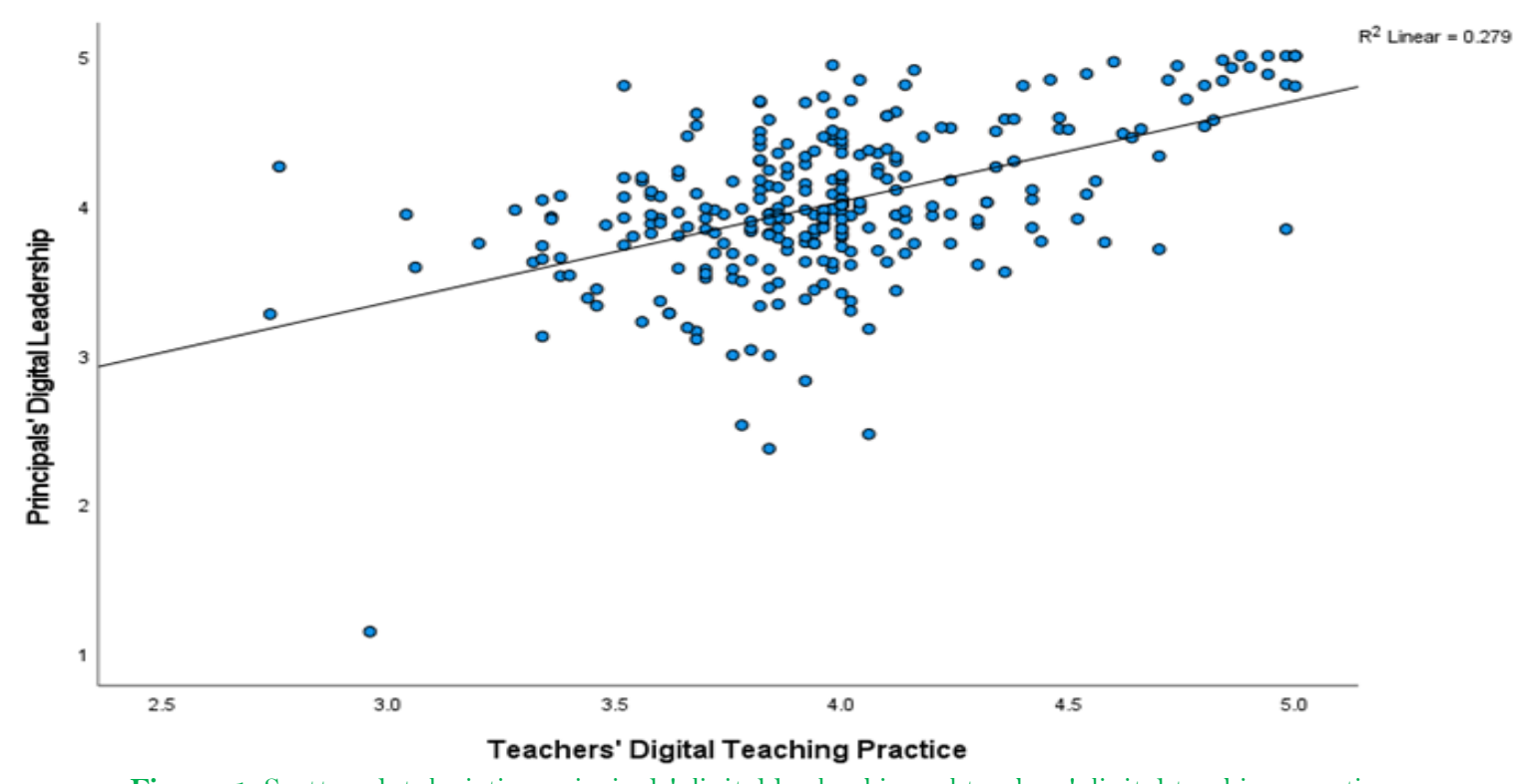

Figure-1. Scatter plot depicting principals' digital leadership and teachers' digital teaching practice.

A further analysis was conducted after all assumptions were met using Simultaneous Multiple regression to identify the dominant predictors of teachers' digital teaching practice out of the various dimensions of the principals' digital leadership (visionary leadership dimensions, digital age learning culture, professional practice excellence, systemic improvement and digital citizenship). This indicated that the effect on teachers' digital teaching practices was statistically significant, $F(5,312)=28.02, p<.001$. The Adjusted $R^{2}$ value was 0.30 , indicating that $30 \%$ of the variance in digital teaching practice could be explained by the model which included five variables in the regression. According to Cohen (1988) this is a large effect. Further analysis, however, found only one variable of digital leadership that was a significant predictor of teachers' digital teaching, namely digital citizenship ( $\square=0.35, p=.000$ ), as presented in Table 3. The finding also indicates that the principal's digital citizenship variable is the strongest predictor of teachers' digital teaching. The model of Teacher Digital Teaching is below, [Teacher Digital Teaching $=2.285+0.241$ digital citizenship $]$.

\begin{tabular}{l|c|c|c}
\multicolumn{4}{c}{ Table-3. Multiple regression coefficients. } \\
\hline Variables & $\boldsymbol{B}$ & $\boldsymbol{S E} \boldsymbol{B}$ & $\boldsymbol{\beta}$ \\
\hline Visionary Leadership & 0.06 & 0.04 & 0.09 \\
\hline Digital Era Learning Culture & -0.01 & 0.05 & -0.02 \\
\hline Professional Practice Excellence & 0.07 & 0.04 & 0.13 \\
\hline Systemic Improvement & 0.06 & 0.05 & 0.10 \\
\hline Digital Citizenship & 0.24 & 0.05 & $0.35^{*}$ \\
\hline Constant & 2.29 & 0.16 & \\
\hline Note: ${ }^{*} p .001$.
\end{tabular}

\section{Discussion}

The principals in the Hulu Langat district have applied the characteristics of digital leadership, namely visionary leadership, digital age learning culture, excellence in professional practice, systemic improvement and digital citizenship in school management and administration. This is in line with the findings of Norakmar et al. (2019) who stated that principals have expressed their willingness to carry out the role of digital leaders in schools. The findings of this study show that teachers agree that principals are involved in the development of strategic planning, especially with regards to the use of ICT and digital technology in teaching. However, teachers are less likely to agree that principals channel information related to the construction of strategic planning by emphasizing the use of ICT and digital technology in teaching. A study by Tibagwa, Onen, and Oonyu (2016), also found that principals need to work with school stakeholders in creating school vision and mission through effective and enhanced strategic planning by implementing the consistent use of technology in academic monitoring, management, and administration by teachers, staff, students, schools and parents.

Teachers agree that principals encourage the use of ICT and digital technology across the curriculum. A study by Cano and García (2013) also pointed out that the management of school organization by using ICT in teacher supervision can help to overcome traditional administrative weaknesses and time constraints, and encourage learning outside the classroom and keeping pace with the developments in ICT and digital technology that continue to dominate the world of education. Digital leadership is seen as an expression of management and administration that can support the latest requirements for digital transformation by ensuring total quality management including motivating, coordinating and evaluating the efforts of all stakeholders in improving teaching and learning, especially during the COVID-19 pandemic (Damayanti \& Mirfani, 2021). 
The digital teaching practice of teachers in the Hulu Langat district is also at a high level. This may support the argument that teachers are beginning to realize the benefits of digital technology-based teaching. Teachers were found to agree that they actively involve students in continuous assessment of their learning processes and thought patterns, in line with Dooley, Lewis Ellison, Welch, Allen, and Bauer (2016). Digital technology-based teaching can help students increase their motivation and thus perform better. The findings of multiple studies have concluded that digital teaching and learning have a significant positive impact on student motivation and learning performance and they recommend leveraging the advantages of digital teaching by developing practical teaching strategies (Hasin \& Nasir, 2021; Khalid \& Quick, 2016; Lin, Chen, \& Liu, 2017; Nasir, Mansor, \& Rahman, 2018). This is in line with the findings of a study by Nasir (2020), which found a significant positive relationship between social presence and student satisfaction through online learning.

Thus, digital teaching can create an active learning atmosphere among students through online or offline learning. Teachers were found to agree that they use digital devices to communicate and collaborate with students, colleagues and parents. These findings are supported by a study by Sung, Chang, and Liu (2016), which found that digital devices can improve the integration of teaching and the effectiveness of student learning. The digital leadership of principals influences the digital teaching practices of teachers. However, there is still room for improvement, especially in the areas of school administration and management. A study by Zhong (2016) also found that principals need to use hybrid methods to support teacher communication and the implementation of teacher standards, including digital teaching, meetings, collaboration groups, the use of social media for administrative matters, online learning and professional development.

Principals who establish professional improvement practices among teachers can increase teachers' confidence to integrate digital teaching and learning. However, Yusof et al. (2019) found that the functions of the digital learning space have not yet reached the minimum requirements - which shows that, in Malaysia, principals have not yet been able to fully implement the constructs of digital leadership. This indicates that the principal needs to fill the gaps that still exist in his management and administration. The findings of the study also indicate that digital learning opportunities and digital learning communities are two indicators of excellence in the professional practice of teachers (Zhong, 2017). Principals need to provide professional development opportunities to ensure that teachers can acquire the practical skills to develop their professional practice.

Principals, therefore, need to devise professional improvement programs to help teachers implement digital teaching practices. This will give teachers the confidence and motivation to continue to practice digital teaching, which will increase the effectiveness of student learning. The findings of this study can be used as a guide for the MOE, IAB, JPN and PPD to organize appropriate leadership programs that will encourage and motivate school administrators to develop their digital leadership characteristics. In this way, education can create a generation with digital capabilities in line with the goals of the National Education Policy to utilize ICT in education to produce knowledgeable and highly skilled citizens. Furthermore, the MOE is committed to strengthening school performance and student achievement by improving the quality and efficiency of the national education system.

\section{References}

Aksal, F. A. (2015). Are headmasters digital leaders in school culture? Education and Science, 40(182), 77-86. Available at: https://doi.org/10.15390/EB.2015.4534.

Arip, M. A. S. M., Saad, F. M., Jaapar, N., Ali, K. M., Athdzar, N. H., \& Rashid, W. N. W. A. (2019). Factors, effects and strategies for dealing with lack of concentration of secondary school students in the classroom: A qualitative study. Journal of Chemical Information and Modeling, 53(9), 1689-1699. Available at: https://doi.org/10.1017/CBO9781107415324.004.

Arokiasamy, A. R. A., Abdullah, A. G. K., \& Ismail, A. (2014). Correlation between cultural perceptions, leadership style and ICT usage by school principals in Malaysia. Turkish Online Journal of Educational Technology, 13(3), 27-40.

Awang, Z., Afthanorhan, A., Mamat, M., Sultan, U., \& Abidin, Z. (2016). The Likert scale analysis using parametric based structural equation modeling (SEM). Computational Methods in Social Sciences, 4(1), 13-21. Available at: https://doi.org/10.5281/zenodo.1299429.

Bahtiar, R. A., Ibrahim, S., Ariffin, H., Ismail, N. H., \& Isa, W. M. K. (2014). Educational goals and Agenda sustained during the Covid-19 movement control order. Retrieved from: https://iab.moe.edu.my/index.php/ms/sumber/menu-berita-pemberitahuan/69pengumuman-2020.

Bass, D. C. (1989). Book reviews. Journal of the American Academy of Religion, 47(2), 429-430. Available at: https://doi.org/10.1093/jaarel/lvii.2.429.

Bernhardt, V. L. (2015). Toward systemwide change - educational leadership. Educational Leadership, 73(3), 56-61.

Cano, E. V., \& García, M. L. S. (2013). ICT strategies and tools for the improvement of instructional supervision. the Virtual Supervision. Turkish Online Journal of Educational Technology, $12(1), 77-87$.

Cohen, J. (1988). Statistical power analysis for the behavioral sciences (2nd ed.). New York: Routledge.

Damayanti, F. P., \& Mirfani, A. M. (2021). An analysis of digital leadership in the pandemic Covid-19 Era. 526(Icream 2020). Paper presented at the In 4th International Conference on Research of Educational Administration and Management (ICREAM 2020).

Domeny, J. V. (2017). The relationship between digital leadership and digital implementation in elementary schools. Doctoral Dissertation, Southwest Baptist University.

Dooley, C. M. M., Lewis Ellison, T., Welch, M. M., Allen, M., \& Bauer, D. (2016). Digital participatory pedagogy: Digital participation as a method for technology integration in curriculum. Journal of Digital Learning in Teacher Education, 32(2), 52-62. Available at: https://doi.org/10.1080/21532974.2016.1138912.

Gupta, S. (2018). Organizational barriers to digital transformation. Doctoral Dissertation, KTH.

Hasin, I., \& Nasir, M. K. M. N. (2021). The effectiveness of the use of information and communication technology (ICT) in rural secondary schools in Malaysia. Journal of Education and e-Learning Research, 8(1), 59-64. Available at: 10.20448/journal.509.2021.81.59.64.

International Society for Technology in Education (ISTE). (2021). International technology standards for administrators. Retrieved from: https://my.iste.org/s/login/?ec=302\&inst=1U\&startURL=\%2Fidp\%2Flogin\%3Fapp\%3Dosp 1UooooooKzRe\%26RelayState\%3D https\%253A\%252F\%252Fwww.iste.org\%252Fsaml_login\%26binding\%3DHttpPost\%26inresponseto\%3D_b2343d5d57e597ada894 $38745 \mathrm{fc} 7 \mathrm{de} 1 \mathrm{a} 95 \mathrm{a} 694 \mathrm{c} 11 \mathrm{f}$.

Jannah, M., Prasojo, L. D., \& Jerusalem, M. A. (2020). Elementary school teachers' perceptions of digital technology based learning in the 2 st Century: Promoting digital technology as the proponent learning tools. Al Ibtida: Jurnal Pendidikan Guru MI, 7(1), 1-18. Available at: https://doi.org/10.24235/al.ibtida.snj.v7i1.6088.

Karahan, E., Canbazoğlu Bilici, S., \& Ünal, A. (2015). Integration of media design processes in science, technology, engineering, and mathematics (STEM) education. Eurasian Journal of Educational Research, 15(60), 221-240. Available at: https://doi.org/10.14689/ejer.2015.60.15.

Khalid, N. M., \& Quick, D. (2016). Teaching presence influencing online students' course satisfaction at an institution of higher education. International Education Studies, 9(3), 62-70. Available at: https://doi.org/10.5539/ies.v9n3p62.

Krejcie, R. V., \& Morgan, D. W. (1970). Determining sample size for research activities. Educational and Psychological Measurement, 30(3), 607-610. 
Leong, M., Chua, Y., \& Sathiamoorthy, K. (2016). Relationship between principal technology leadership practices and teacher ICT competency. Malaysian Online Journal of Educational Management, 4(3), 13-36. Available at: https://doi.org/10.22452/mojem.vol4no3.2.

Lin, M. H., Chen, H. C., \& Liu, K. S. (2017). A study of the effects of digital learning on learning motivation and learning outcome. Eurasia Journal of Mathematics, Science and Technology Education, 13(7), 3553-3564. Available at: https://doi.org/10.12973/eurasia.2017.00744a.

Ministry of Education Malaysia. (2019). Executive summary: ICT transformation plan 2019-2023. In Pelan Transformasi ICT. Retrieved from: https://www.moe.gov.my/penerbitan?search=\&category=.

Nasir, M. K. M. (2020). The influence of social presence on students' satisfaction toward online course. Open Praxis, 12(4), $485-493$.

Nasir, M. K. M., Mansor, A. Z., \& Rahman, M. J. A. (2018). Measuring Malaysian online university student social presence in online course offered. Journal of Advanced Research in Dynamical and Control Systems, 10(12), 1442 - 1446.

Norakmar, O. M., Noor, I. S., \& Latif, K. A. (2019). The relationship of principal technology leadership and teacher self -efficacy. Journal of Educational Leadership, 6(4), 1-21.

Norakmar, M., Noor, I. O., S., \& LAtif, K. A. (2020). The technology leadership character of principals in ict integration in secondary schools. Journal of Educational Leadership, 7(1), 28-46.

Organisation for Economic Cooperation and Development [OECD]. (2019). Learning in a digital environment. 177-229. Retrieved from: https://doi.org/1 10.1787/1788f1586c1786-en.

Petersen, A.-L. (2014). Teachers' perceptions of principals' ICT leadership. Contemporary Educational Technology, 5(4), 302-315. Available at: https://doi.org/10.30935/cedtech/6132.

Sallehin, S. A., Halim, A., Education, F., Tun, U., \& Onn, H. (2015). The use of multimedia -based teaching aids in teaching and learning in Benut Zone Secondary School. Faculty of Technical and Vocational Education (pp. 1-7): Universiti Tun Hussein Onn Malaysia.

Sheninger, E. (2014). Digital leadership: Changing paradigms for changing times. Paper presented at the INTED2019 Proceedings.

Sung, Y.-T., Chang, K.-E., \& Liu, T.-C. (2016). The effects of integrating mobile devices with teaching and learning on students' learning performance: A meta-analysis and research synthesis. Computers \& Education, 94, 252-275. Available at: https://doi.org/10.1016/j.compedu.2015.11.008.

Thannimalai, R., \& Raman, A. (2018). Principals technology leadership and teachers technology integration in the 21 st century classroom. International Journal of Civil Engineering and Technology, 9(2), 177-187. Available at: https://doi.org/10.29333/iji.2019.12428a.

Tibagwa, K. N., Onen, D., \& Oonyu, J. (2016). Head teacher's leadership styles and the quality of teacher support supervision. International Journal of Education and Research, 4(8), 63-78.

Tomte, C. (2013). Digital competence in teacher education. Paper presented at the Learning \& Teaching with Media \& Technology - ATEESIREM Winter Conference Proceedings.

Van Niekerk, E. J., \& Van Wyk, M. M. (2014). Staff's perceptions of vision and long term principal leadership in South African schools: An exploratory study. Mediterranean Journal of Social Sciences, 5(4), 406-414. Available at: https://doi.org/10.5901/mjss.2014.v5n4p406.

Victoria State Government. (2020). Teach with digital technologies. Victoria State Government. Retrieved from: https://www.education.vic.gov.au/school/teachers/teachingresources/digital/Pages/teach.aspx.

Vinathan, T. A. (2017). The relationship between teacher motivation and the use of ICT in teaching in SJK (T) Kuala Muda Yan District. Proceedings of the ICECRS, 1(1), 1043-1054. Available at: https://doi.org/10.21070/picecrs.v1i1.647.

Yusof, M. R., Yaakob, M. F. M., \& Ibrahim, M. Y. (2019). Digital leadership among school leaders in Malaysia. International Journal of Innovative Technology and Exploring Engineering, 8(9), 1481-1485. Available at: https://doi.org/10.35940/ijitee.i8221.078919.

Zhong, L. (2016). The effectiveness of digital leadership at K-12 schools in Mississippi regarding communication and collaboration during CCRS implementation. Dissertation Abstracts International Section A: Humanities and Social Sciences, 77(8-A(E).

Zhong, L. (2017). Indicators of digital leadership in the context of K-12 education. Journal of Educational Technology Development and Exchange (JETDE), 1O(1), 1-27. Available at: https://doi.org/10.18785/jetde.1001.03. 